\title{
Applications of robots in urology
}

\author{
Rahul Thaly $\cdot$ Ketul Shah $\cdot$ Vipul R. Patel
}

Accepted: 24 November 2006/ Published online: 2 February 2007

(C) Springer London 2007

\section{Introduction}

During the last two decades the field of urology has seen a tremendous growth in minimally invasive surgery. Potential advantages with this shift toward laparoscopic surgery include smaller incisions, reduced blood loss, less post-operative pain with reduced intake of narcotics, shorter hospital stays, and faster recovery. Nephrectomy, adrenalectomy, pyeloplasty, and prostatectomy have all established themselves as procedures benefitting from minimally invasive surgery. Complex laparoscopic procedures, for example prostatectomy, have proven to be quite a daunting task, because of the steep learning curve for many urologists [1]. Factors limiting the performance of standard laparoscopic radical prostatectomy are counter-intuitive motion, the lack of depth perception secondary to $2 \mathrm{D}$ vision, and rigid instrumentation with only four degrees of surgical freedom. These factors hinder visualization, dissection, and suturing in small spaces [1].

Introduction of robotic technology into modern day surgery has removed many of these technical barriers and has the potential to facilitate the broad-based adoption of complex laparoscopic procedures. There are more than 400 robotic systems in the USA and over 30,000 robotic procedures have been performed

R. Thaly · K. Shah · V. R. Patel ( $\square)$

Center for Robotic and Computer Assisted Surgery,

Division of Urology, Ohio State University,

538 Doan Hall, 410 West 10th Avenue,

Columbus, OH 43210-1228, USA

e-mail: Patel.914@osu.edu

(communication with Intuitive Surgical). Although, initially, the equipment was conceived for use in cardiac surgery, adoption has been strongest in urology. It seems that robotic surgery has been uniquely adapted to urology, especially prostatectomy, because of the unique advantage of miniature instruments in the pelvis. Although prostatectomy is the main use of robotic surgery in urology its use in other urologic procedures is expanding rapidly as surgeons become more adept with its use. We review the current status of robotic technology, the constraints to its use and the surgical applications of robotic technology in urology.

\section{History of robotics}

The word robot comes from the Czech word "robota" meaning compulsory labor. By strict definition, in the Oxford English Dictionary, a robot is a mechanism guided by automatic control. The classic impression of a robot is a mechanical device that performs pre-programmed repetitive tasks. These attributes are often used in industry to "mass produce and improve efficiency" in, for example, auto assembly plants and computer manufacturing. In surgery robots have a different role, because of different demands and applications. Surgical robots must have the capability of a human interface to enable real-time guidance in different scenarios. Modern day surgical robots are a form of computer-assisted surgery in which, by using a "master-slave relationship", the surgeon can control the actions of the robot in real time, using the robot to improve his/her vision, dexterity, and overall surgical precision. 


\section{Robotic applications in surgery}

The first generation of surgical robotic assistance was tested in the mid to late 1980s in the fields of neurosurgery, urology, and orthopedic surgery. In neurosurgery many systems have been used as neuronavigators, stereotactic localizers, and robotic assistants in surgery. The first system was used in 1985 and was called the Puma 560. It was used to orient a needle for a brain biopsy under computerized tomography guidance [2]. In 1989 a group at Imperial College (London, UK) developed the concept of using a robot (Probot) in urology to perform transurethral resection of the prostate [3]. Because the prostate is a relatively fixed organ and the procedure requires repetitive movements this operation was a good candidate for robotic intervention.

In orthopedics the RoboDoc system (Integrated Surgical Systems, Sacramento, CA, USA) was designed to address potential human errors in performing cement-less total hip replacements [4]. This system helped the surgeon mill a hole in the femur and thus produce cavities that were ten times more accurate than could be achieved by manual reaming [5].

As the development of robotics progressed, more advanced robotic systems with a broader array of clinical applications appeared. The new era of telepresence surgery, that enables the surgeon to operate at a distance from the operating room, was simultaneously developed at the Stanford Research Institute, the Department of Defense, and the National Aeronautics and Space Administration (NASA) [6]. The initial purpose was to create a prototype to suit the needs of the military, and the robotic arms were designed to be mounted on an armored vehicle to provide immediate operative care in the battlefield. Surgeons would be able to use the telepresence technology to operate in the battlefield from a safe distance. Soon thereafter, Intuitive Surgical acquired the prototype and commercialized the system called da Vinci.

\section{Commercially available robots}

Robotic integrated surgical system

In the early 1990s Computer Motion (Goleta, CA, USA) developed the Zeus robot which is a masterslave system. It was specifically designed for cardiac operations, for example coronary artery bypass grafting; later, however, it was diversified for several surgical specialties, for example general surgery, urology, and gynecology [7]. This system consists of a control unit, an Aesop robotic arm for a camera, and two robotic arms which are directly mounted on the operating table. Standard Zeus instruments have four degrees of freedom. The Zeus system has two subsystems "the surgeon-side" and the "patient-side". The surgeon's subsystem consists of a console that can be positioned anywhere in the operating room. The console consists of a video monitor and two handles that control the robotic arms holding the surgical instruments. The patient-side subsystem consists of three robotic arms attached to the table. The disadvantages of the initial Zeus system included instruments lacking intraabdominal articulation and the console containing a $2 \mathrm{D}$ viewing monitor. Three-dimensional vision and instruments with intra-abdominal articulation capabilities were added to later versions of the surgical system. This system is currently no longer commercially available.

Immersive telerobotic surgical system

In 2000 the FDA approved the da Vinci robotic system (Fig. 1a, b), a type of master-slave system, for clinical use.
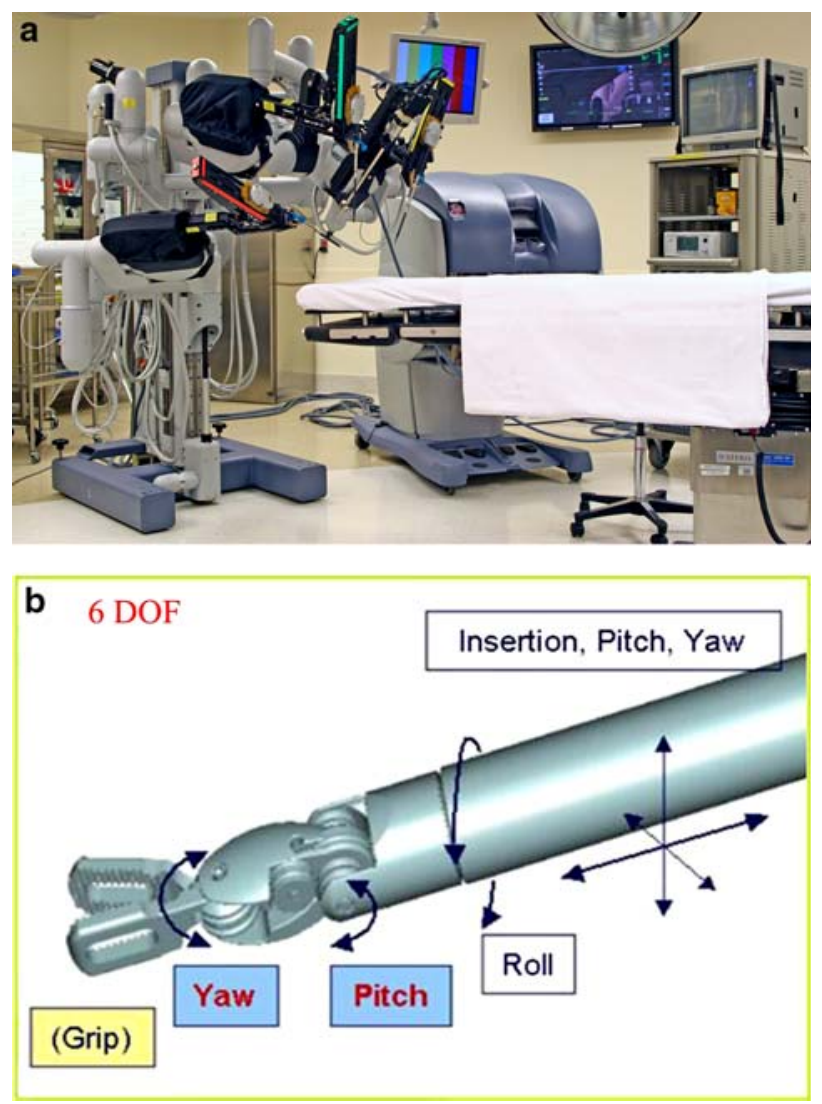

Fig. 1 a da Vinci robot, b range of motion 
The da Vinci system is based on three components:

1 a master-slave, software-driven system that enables intuitive control of laparoscopic instruments with six degrees of freedom;

2 a stereoscopic vision system displayed in an immersive format; and

3 a system composed of redundant sensors to provide maximum safety in operation [8].

The system consists of three separate units [9]:

Console he console is positioned remotely from the patient and connected by a cable to the video cart and the surgical cart. The FDA requires that in the United States all operations using the da Vinci surgical system be performed in the same room as the patient. The console houses a stereoviewer, which has an infrared beam to deactivate the robotic arms whenever the surgeon moves his head out of the console. The surgeon's hands are inserted into free-moving "masters" or finger controls, which convert the movements of the surgeon's wrist and fingertips into electric signals. These are then converted to computer commands to direct the robotic instruments to perform the same movements in the operative field. The console has controls for 3D viewing, the height of the console, the ability to choose a $0^{\circ}$ or $30^{\circ}$ laparoscope, motion scaling (5-1 means that five units of motion of the surgeons hands are reduced to one unit of motion for the instruments), and tremor filtration. There is an ability to control the camera, energy devices, and the "masters" with foot pedals.

Video cart The video cart has two video camera control boxes and two light sources, in addition to a synchronizer.

Surgical cart The surgical cart supports either three or four robotic arms. Surgical instruments are attached to the robotic arms through an adapter, which uses an 8-mm da Vinci-specific port. The central robotic arm houses a $12 \mathrm{~mm}$ telescope, which contains two separate 5-mm telescopes for 3D vision. The robotic surgical instruments are capable of intraabdominal articulations with seven degrees of freedom. The robotic instruments can be used for up to ten cases after which they must be replaced.

Disadvantages include the lack of tactile feedback, bulky robotic arms with large excursion arcs that can lead to collisions, limited instrumentation, and the inability to move the surgical table when the robot arms are attached to the ports. The large size of the robot also limits the ability of surgical assistants to maneuver around the patient.

\section{Robotic urology procedures}

\section{Prostatectomy}

During the last half decade robotic prostatectomy has become the backbone of robotic surgical applications in urology. Robotic prostatectomy is viewed as the most natural application, because the small-wristed instrumentation and magnified 3D view have significant advantages when working deep in the pelvis.

Radical retropubic prostatectomy is currently the best treatment for clinically localized carcinoma of the prostate [10]. It has been shown to have significant survival benefit in those treated in the early stages of the disease. Robotic radical prostatectomy has the potential to challenge this as the best treatment, because of its minimally invasive nature and promising short-term outcomes, which include operative time, blood loss, length of hospital stay, post-operative pain, continence, potency, and oncologic outcomes.

\section{Peri-operative outcomes}

\section{Operative time}

It is difficult to compare operative times between different series because of variations in the reporting of operative time, including setup and/or pelvic lymph node dissection. The mean operative time for reported robotic series ranges from 141 to $540 \mathrm{~min}$ [11-23], however, and decreases substantially with increasing surgeon experience. In our initial experience of 200 cases, operative time declined from a mean of 202 min for our first 50 cases to $141 \mathrm{~min}$ for the last 50 [23]. With our series now growing to over 1,000 cases mean operative times have been further reduced to less than 90 min (unpublished data). Ahlering et al. [18] have reported a similar experience-related reduction in operative time with a mean of $184 \mathrm{~min}$ for their last ten cases compared with the overall mean operative time of $207 \mathrm{~min}$. For experienced surgeons there does not seem to be a significant difference between operative times for RRP and RALP, with both routinely being performed in less than $3 \mathrm{~h}[22,24]$.

\section{Blood loss and transfusion}

Autologous blood transfusion carries a small but significant risk of transfusion reaction and infection with HIV or hepatitis C. Reduction of the need for transfusion is thus of benefit to the patient (Fig. 2). Reduced intraoperative blood loss has been regarded as one of 


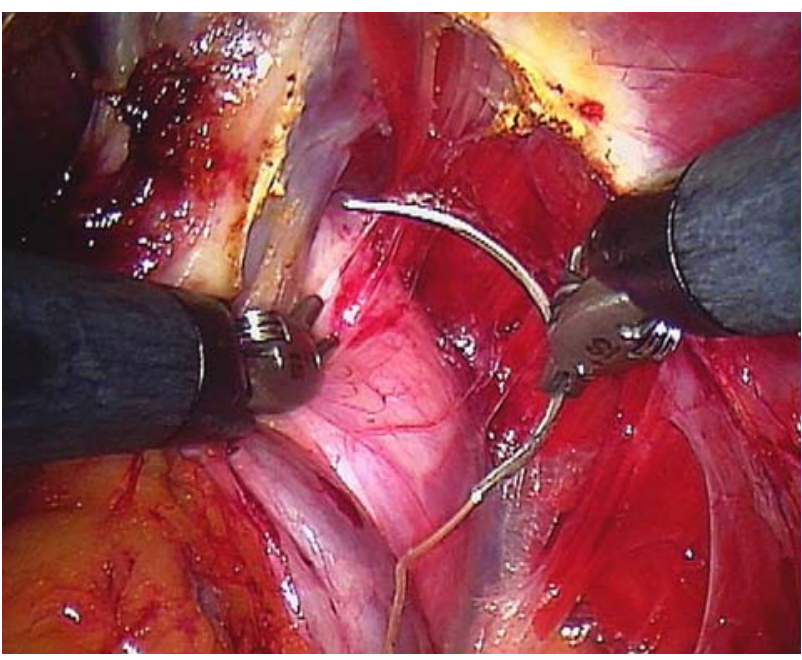

Fig. 2 Dorsal vein ligation

the hallmark advantages of laparoscopic prostatectomy [11]. Early identification and precise ligation of vessels facilitates this limitation of blood loss (Fig. 2). The tamponade effect of the pneumoperitoneum helps diminish blood loss from venous sinuses. Transfusion after RALP has been reported to be $0-17 \%$ [11-16, 18-23, 25], with $0 \%$ transfusion for six of these studies $[15,18,19,22,25,26]$. In a comparative study for a single surgeon, Tewari et al. [24] report a significantly higher rate of transfusion after RRP (67\%) than after RALP (0\%). The mean estimated blood loss in the RALP series was $75 \mathrm{~mL}(10-900 \mathrm{~mL})$, with most being less than $200 \mathrm{~mL}$ [11-16, 18-20, 22, 23, 25].

\section{Length of hospital stay}

Length of hospitalization is an important component of convalescence after surgery and is often regarded as a measure of patient well-being. Shorter hospitalization is indicative of less morbidity and faster recovery. It is, however, often variable and depends on the type of surgery, the clinical pathway, surgeon practice patterns, and cultural differences. The usual length of stay after an open surgical approach varies between 1 and 3 days. In more recent RALP series in the USA the mean length of stay (LOS) has been reported to be 1.08-1.5 days, declining with increasing surgical experience [15-20, 22, 23]. Ahlering et al. [22] reported shorter LOS in patients after RALP than after RRP (25.9 compared with $52.8 \mathrm{~h}$ ) performed by the same surgeon. Tewari et al. [24] reported similar findings with mean LOS for the RALP group being 1.2 days compared with 3.5 days for the RRP group. Similarly, our LOS was 1.2 days, with $95 \%$ of the patients being discharged on post-operative day one.
Post-operative pain

As with most minimally invasive procedures, RALP is performed through several small incisions and is associated with minimal post-operative pain. In the few published studies, there are conflicting reports on reduction of post-operative pain with RALP. In studies by Menon et al. there was a statistically significant difference in visual analog pain score on post-operative day one with RALP, with a mean score of three $[1,27$ 32], compared with RRP, with a mean score of seven $[15,19]$. In a study by Webster et al. the converse was reported, with no statistical difference between pain on the day of surgery; using the Likert pain scale RALP had a mean score of 2.52 compared with 2.88 in the RRP group [33]. Prospective analyses comparing the two are currently pending.

\section{Continence}

One primary surgical objective when performing prostatectomy is maintenance of continence. This is often a significant area of concern for the patient when considering treatment options. Precise mucosa to mucosa approximation and optimum preparation of the urethral stump are important in preservation of continence and prevention of stricture [34]. Younger age, preservation of the neurovascular bundle, and absence of pre-operative stricture have also been reported to increase the chance of retaining or regaining continence after surgery [35].

In earlier series of RRP, occurrence of incontinence based on patient-reported surveys was as high as $50 \%$ [36-39]. Walsh et al. [10] reported continence (no pad usage in past 4 weeks) to be $54 \%$ at 3 months, $80 \%$ at 6 months, $93 \%$ at 12 months, and $93 \%$ at 18 months. No pad use three months after RRP has been reported to be between 50 and $76 \%$ [22, 40, 41]. For most series, continence after RRP is reported to be greater than $90 \%$ and in one series was as high as $95 \% 12$ months post-operation [35, 40, 42-46].

It has been proposed that RALP can potentially result in better continence or an earlier return of continence as a result of improved preservation of urethral sphincter, increased urethral length (Fig. 3), and a water-tight anastomosis. Ahlering et al. [18] have reported continence of 33,63 , and $81 \% 1$ week and 1 and 3 months after RALP. In a comparative study, Ahlering et al. [22] found no significant difference between overall continence after RALP (76\%) compared with RRP (75\%) when performed by the same surgeon. Tewari et al. [24], however, have shown return to continence to be quicker in the RALP group 


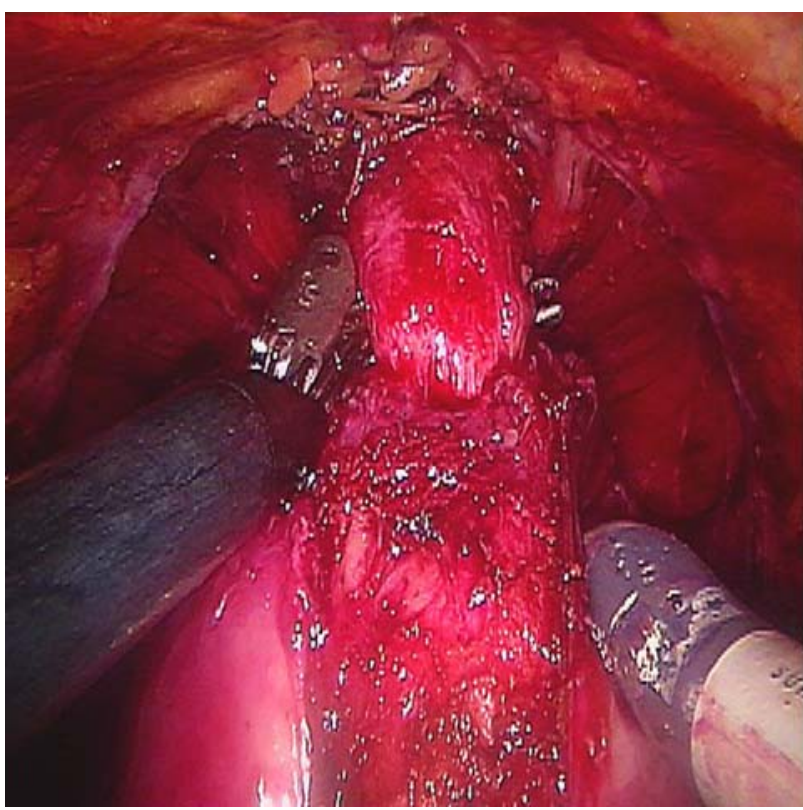

Fig. 3 Long urethral stump

with $50 \%$ being continent at 44 days compared with 160 days for RRP. In the landmark initial reports of RALP, Pasticier [11] reported $80 \%$ of patients to be continent 9 days post-operation and Binder [13] reported 50\% continence at 1 month. Menon et al. [34] have recently reported continence (no pads) of $96 \%$ 3 months post-operation. In our study of 200 patients, continence (no pads) at 1,6 , and 12 months was 47,89 , and $98 \%$, respectively [23].

\section{Potency}

Theoretically, de-novo erectile dysfunction after prostatectomy occurs because of injury of the neurovascular bundles. Such damage can occur as a result of thermal or traction injury, direct incision, or incorporation of the nerve into hemostatic sutures or clips. Younger age, better pre-operative potency, and extent of neurovascular bundle preservation are factors that have been shown to affect post-operative return of erectile function [47]. It has been proposed that RALP may prevent damage to the neurovascular bundle. Dissection occurs in an antegrade fashion, reducing traction on the nerve. Better vision, because of magnification and reduced blood in the surgical field, enables more precise dissection, preventing inadvertent incision or incorporation into the suture (Fig. 4).

Potency outcomes are difficult to compare across series because of differences between definitions of potency and patient selection. Overall potency after RRP is reported to be $62-68 \%$ at high volume centers

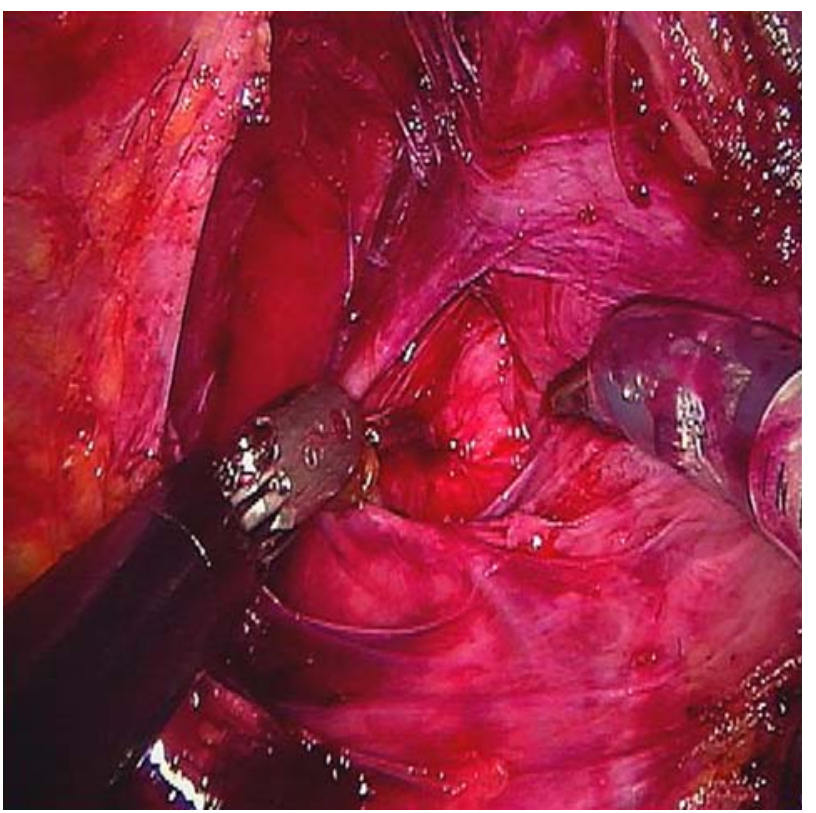

Fig. 4 Neurovascular bundle

but has been reported to be as low as $10-30 \%$ in patient reported-surveys [25, 36-39, 42-45].

In series by Quinlan et al. [48] potency was $90 \%$ for men younger than 50 undergoing RRP with preservation of one or both neurovascular bundles but was lower for men older than 50, especially if both neurovascular bundles were not preserved. Walsh et al. [10] have also reported overall potency, defined as intercourse with or without the use of sildenafil, to be $38 \%$ at 3 months, $54 \%$ at 6 months, $73 \%$ at 12 months, and $86 \%$ at 18 months.

In a recent series of 565 RALP, Menon and Tewari [15] report that $82 \%$ of preoperatively potent patients younger than 60 (and $75 \%$ older than 60 ) had return of some sexual activity by their 6 month follow-up. In their prospective series comparing RRP to RALP, Tewari et al. [24] reported a more rapid return of erection after RALP (50\% return at a median followup of 180 days for RALP compared with 440 days for $\mathrm{RRP})$ and more rapid return to intercourse $(50 \%$ at 340 days for RALP compared with $<50 \%$ at $>700$ days for RRP). Most recently, Menon et al. [49] reported $97 \%$ potency one year after RALP for men with a preoperative sexual health inventory for men (SHI-M) score greater than 21 .

\section{Oncologic outcomes}

Most contemporary open RRP series report overall margin positive rates (MPR) of $12-25 \%$ [47]. In a lit- 
erature review, Wieder and Soloway reported positive margin rates after RRP to range from 0 to $77 \%$ with an overall average of $28 \%$ in reviewed RRP series [2]. In this review, they also report margin positive rates (MPR) for T2a disease to be $0-38 \%$ with an average of $17 \%, 11-77 \%$ with an average of $36 \%$ for $\mathrm{T} 2 \mathrm{~b}$, and $25-$ $59 \%$ with an average of $53 \%$ for T3 disease. Han et al. [3] have reported MPR as low as $2.7 \%$ for T2 disease after RRP.

The reported MPR after RALP series range from 0 to $36 \%$ [11-16, 18-23, 25]. When stratified by stage, MPR after RALP ranges from 0 to $17 \%$ for T2a, $0-33 \%$ for T2b, $0-82 \%$ for T3a, $20-50 \%$ for T3b, and $33-67 \%$ for T4 [11-16, 18-23]. Ahlering et al. [18] reported a trend toward a higher rate of positive surgical margins in the open RRP group (20\%) compared with the RALP group (16.7\%), although it did not reach statistical significance. In our series of 200 patients the positive margin rate for T2, T3a, T3b, and T4 tumors was $5.7,29,20$, and $33 \%$, respectively [23]. As our technique has been refined and our series has grown we have seen improved MPRs for T2 disease. In our series of 500 patients, the positive margin rate was $9.4 \%$ for the entire series (unpublished results). The positive margin rate was $13 \%$ for cases $1-100,8 \%$ for $101-200,13 \%$ for $201-300,5 \%$ for $301-400$, and $8 \%$ for $401-500$. For organ-confined disease (T2) the margin positive rate was $2.5 \%$ and for non-organ confined disease it was $31 \%$. There were a total of 47 positive margins, 26 (56\%) posterolateral, 4 (8.5\%) apical, 4 (8.5\%) bladder neck, 2 (4\%) seminal vesicle, and 11 (23\%) multifocal.
For the RALP to be accepted as a satisfactory alternative to current best practice, oncologic outcomes must be proven to be uncompromised. Although initial reports (Table 1) have shown promise with surrogate markers, for example positive margin rate and short-term prostate-specific antigen (PSA) recurrence data, long-term outcomes are currently unavailable. Because the procedure is only 5 years old, the PSA recurrence data are immature and will not be available in the near future. We must therefore monitor progress closely over the coming years before reaching a definitive conclusion.

\section{Robotic renal surgery}

Another potential application of the use of robotics is in renal surgery. Guillonneau and colleagues [4] performed the first robot-assisted laparoscopic nephrectomy in humans using the Zeus system (Computer Motion) in 2001. In 2002, Horgan et al. [5] reported their early experience in 12 successful cases of robotic living donor nephrectomy (Table 2). The authors concluded that the length of the dissected vessels, and therefore the quality of the allograft, is improved as a result of enhancement of the dexterity of the robot. Despite this, adoption of robotic radical nephrectomy has not occurred as quickly as with prostatectomy. This is probably because the technical advantages, suturing and reconstruction, provided by the robotic approach are not often needed during nephrectomy.

Table 1 Operative characteristics and outcomes of RALP

\begin{tabular}{|c|c|c|c|c|c|c|c|c|c|c|c|}
\hline Investigators & $\begin{array}{l}\text { Patients } \\
(N)\end{array}$ & $\begin{array}{l}\text { Age } \\
\text { (years) }\end{array}$ & $\begin{array}{l}\text { PSA } \\
\left(\mathrm{ng} \mathrm{L}^{-1}\right)\end{array}$ & Access & $\begin{array}{l}\text { Operative } \\
\text { time } \\
(\mathrm{min})\end{array}$ & $\begin{array}{l}\text { Blood } \\
\text { loss } \\
(\mathrm{mL})\end{array}$ & $\begin{array}{l}\text { Transfusion } \\
\text { rate }(\%)\end{array}$ & $\begin{array}{l}\text { Hospital } \\
\text { stay } \\
\text { (day) }\end{array}$ & $\begin{array}{l}\text { Catheter } \\
\text { time } \\
\text { (day) }\end{array}$ & $\begin{array}{l}\text { Complications } \\
(\%)\end{array}$ & $\begin{array}{l}\text { Positive } \\
\text { margin } \\
(\%)\end{array}$ \\
\hline Binder [13] & 10 & 60.5 & 6.4 & $\mathrm{TP}$ & $540^{\mathrm{a}}$ & NR & 10 & NR & 18 & 10 & 30 \\
\hline Menon [15] & 200 & 59.9 & 6.2 & $\mathrm{TP}$ & $160^{\mathrm{a}}$ & 153 & 0 & 1.2 & 7 & 4 & 6 \\
\hline Wolfram [20] & 81 & 63 & 8.96 & $\mathrm{TP}$ & 250 & 300 & 12 & NR & 14 & NR & 22.2 \\
\hline Aherling [22] & 60 & 62.9 & 8.1 & $\mathrm{TP}$ & 231 & 105 & 0 & 1.08 & 7 & 6.7 & 16.7 \\
\hline Cathelineau [25] & 105 & NR & 8 & TP/EP & 180 & 500 & 6 & 5.5 & 7 & 6.7 & 22 \\
\hline Patel [23] & 200 & 59.5 & 7.1 & $\mathrm{TP}$ & 141.2 & 75 & 0 & 1.1 & 7.2 & 1 & 10.5 \\
\hline
\end{tabular}

${ }^{a}$ Includes pelvis lymph node dissection

Table 2 Operative characteristics and outcomes of robot-assisted donor nephrectomy

\begin{tabular}{llllllll}
\hline Investigators & $\begin{array}{l}\text { Patients } \\
(N)\end{array}$ & $\begin{array}{l}\text { OR time } \\
(\mathrm{min})\end{array}$ & $\begin{array}{l}\text { Warm ischemia } \\
\text { time }(\mathrm{min})\end{array}$ & $\begin{array}{l}\text { Blood } \\
\text { loss }(\mathrm{mL})\end{array}$ & Complications & $\begin{array}{l}\text { Hospital } \\
\text { stay (day) }\end{array}$ & $\begin{array}{l}\text { Return to } \\
\text { activity (day) }\end{array}$ \\
\hline Horgan [5] & 12 & 166 & 79 & 68 & $\begin{array}{c}\text { Ileus in 1 patient, wound } \\
\text { infection 1 patient } \\
\text { DVT in 1 patient }\end{array}$ & $\begin{array}{l}1.91 \\
26.3\end{array}$ \\
Renoult [75] & 13 & 185.5 & 435 & Min & 5.84 & NR \\
\hline
\end{tabular}


Laparoscopic partial nephrectomy is a technical challenge to even the most experienced laparoscopic surgeons. The need to excise renal tissue while maintaining hemostasis, and the potential need to suture laparoscopically, has proven challenging. While many have been able to master the standard laparoscopic approach to partial nephrectomy, others have found it technically challenging. Robotic assistance has the potential to make learning easier and help the laparoscopic approach to partial nephrectomy become more widely accepted and utilized.

Robotic partial nephrectomy is still in its infancy and few series have been reported (Table 3). Stifelman and colleagues [6] recently reported their experience with robot-assisted laparoscopic partial nephrectomy (RALPN). Twelve RALPN were performed. Intraoperative hilar clamping was used in all cases. With the da Vinci system, the tumor was excised with cold scissors and biopsies were taken from the base. The kidney was then reconstructed and the defect was sutured with the robot, if necessary. For larger defects with more significant bleeding, a Surgicel bolster was laid in the defect and mattress sutures were placed before releasing the clamp. The mean operative time was $265 \mathrm{~min}$, the mean warm ischemia time was $26 \mathrm{~min}$, the mean tumor size was $1.8 \mathrm{~cm}$, the mean estimated blood loss was $240 \mathrm{~mL}$, the mean decrease in hematocrit was $6.5 \%$, and the mean length of stay was 2.7 days. One patient developed a urine leak that was managed with a percutaneous drain for 5 weeks. Their conclusion was RALPN was safe, feasible, and reproducible.

Peschel and colleagues [7] also reported their experience with 13 partial nephrectomies (12 purely robotic) with a mean lesion size of $3.5 \mathrm{~cm}$. The mean warm ischemia time was $22 \mathrm{~min}$ and cold ischemia time ranged from 18 to $43 \mathrm{~min}$. Mean estimated blood loss was $170 \mathrm{~mL}$. Mean operating time was $215 \mathrm{~min}$, ten cases had malignancies. No intraoperative complications were encountered. One patient experienced a post-operative ileus, which resolved spontaneously without adverse consequences. There was one positive margin which was treated with complete nephrectomy.

More recently Caruso et al. [8] compared ten patients who underwent robot-assisted laparoscopic partial nephrectomy (RALPN) with ten patients who underwent conventional laparoscopic partial nephrectomy (LPN). Operative time, ischemia time, and EBL were similar for both groups. There were two intraoperative complications in the RALPN group. In one case bleeding after removal of the vascular clamps necessitated conversion to a hand-assisted approach. EBL was $300 \mathrm{~mL}$ and post-operative hematocrit was

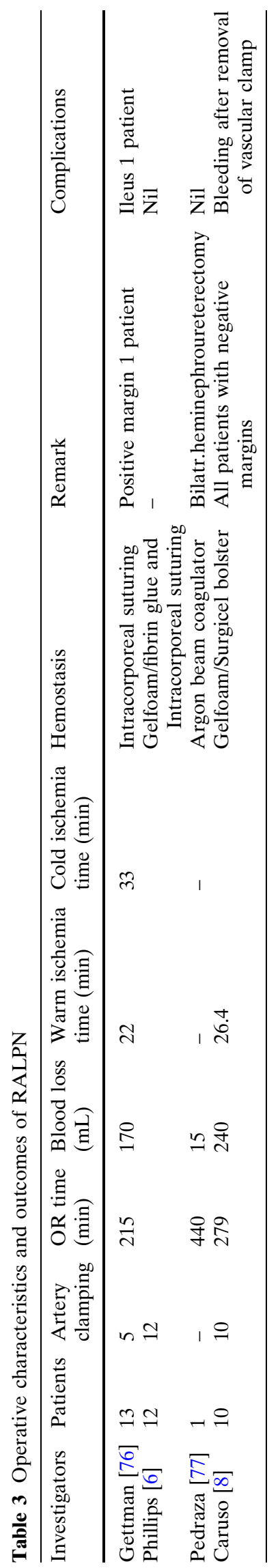


$31.7 \mathrm{~mL} \mathrm{dL}^{-1}$. In the other case back bleeding and poor visualization required conversion to an open procedure. EBL was $500 \mathrm{~mL}$ and post-operative hematocrit was $34 \mathrm{~mL} \mathrm{dL}^{-1}$. In the LPN group there was one conversion to open surgery for excessive back bleeding. All patients in the robotic group had negative margins. One patient in the laparoscopic group had a negative intraoperative margin but was found to have a positive margin on formal pathological review of the entire specimen.

From these studies it is clear that it is feasible to use robotic surgery to perform partial nephrectomy; its overall efficacy, utility and advantages over conventional surgery, however, are still unknown. It seems ischemia time, operative time, and blood loss are similar for the robotic and standard laparoscopic groups. Larger randomized series must be performed to determine whether the robotic system results in other advantages that were not detected in the small series that are currently available for review.

\section{Robot-assisted pyeloplasty}

As laparoscopic pyeloplasty has evolved for treatment of UPJ obstruction, an increasing number of urologists have attempted to learn this operation. For novice laparoscopists learning is often quite difficult, because of the limitations of conventional laparoscopic surgery. The robot was initially looked upon as a tool to enable transition of surgeons from open to laparoscopic surgery. Studies soon showed, however, that the robot was not just a transition tool but in many ways was an improvement compared with standard laparoscopy, and with broader application.

The first robot-assisted pyeloplasty was described by Sung et al. [9]. Their porcine model compared only the pyeloureteric anastomosis time and "tightness" of the anastomosis between traditional intracorporeal laparoscopic suturing and robot-assisted suturing. Use of the robot resulted in increased anastomosis times, but the "tightness" of the anastomosis was equal for two groups of pigs on visual inspection with indigo carmine and ex-vivo retrograde ureteropyelogram. The robot in this work was the Zeus robot with an Aesop attachment. Soon afterward this same group compared the Zeus and da Vinci robots for performing various laparoscopic procedures on the porcine model [50]. They were able to perform the anastomosis faster and secure it with more bites by using the da Vinci system. Comparison of the two systems revealed the da Vinci robot was more technically intuitive to use, which made learning quicker.

\section{Clinical outcomes}

The initial human series described the classical Anderson-Hynes [51] dismembered pyeloplasty in nine patients using the da Vinci robot. Five of these patients underwent retrograde stent placement just before the operation and the other four had antegrade stents placed laparoscopically. They used three ports for the robot and one port for the assistant. Mean operative time was $138.8 \mathrm{~min}$, mean suture time was $62.4 \mathrm{~min}$, average blood loss was less than $50 \mathrm{~mL}$ in all cases, and mean hospital stay was 4.7 days. One patient required open exploration and repair for a persistent renal pelvis defect after pyeloplasty. Follow-up at 3 months was complete in five patients. All five patients had subjective and imaging proven improvement. The authors included neither radiological criteria for UPJ obstruction nor criteria for obstruction improvement. They proved, however, that robot pyeloplasty had the ability to emulate the open procedure similar to laparoscopic pyeloplasty (Table 4).

Gettman et al. [52] later compared robot pyeloplasty with standard laparoscopic pyeloplasty. Six patients in the robot group were compared with similar laparoscopic patients. Four patients underwent dismembered pyeloplasty and two underwent Fenger pyeloplasties. All patients were stented immediately before the operation. Mean operative time and suturing time was less for the robot pyeloplasties, but blood loss, hospital stay, and complications were similar. Suturing and operative time differences between robotic and standard laparoscopic pyeloplasty may have been even greater, because all standard laparoscopic procedures underwent extracorporeal tying rather than robotic intracorporeal tying. Short-term subjective and imaging results at 3 months were indicative of $100 \%$ success. They updated this series 2 years later with a total of 49 patients [53]. Ten of these patients had initially failed endopyelotomy. Mean operative time was $124 \mathrm{~min}$. Estimated blood loss was less than $50 \mathrm{~mL}$. Follow-up for 41 of the 49 patients at a mean of 7.4 months revealed $100 \%$ success with diuretic renal scan or IVP.

After these early successes several other groups began reporting their experiences with robot-assisted laparoscopic pyeloplasty. Most of these groups performed a hybrid approach with initial dissection of the bowel, renal pelvis, and proximal ureter being performed using standard laparoscopic techniques and then use of the robot to perform the ureteropelvic anastomosis. Their short-term outcomes were similar with at least $94 \%$ success and minimal complications. The University of Miami reported results for 26 pa- 
Table 4 Operative characteristics and outcomes of robot-assisted pyeloplasty

\begin{tabular}{|c|c|c|c|c|c|c|c|c|}
\hline Investigators & $\begin{array}{l}\text { Patients } \\
(N)\end{array}$ & $\begin{array}{l}\text { OR } \\
\text { time } \\
(\mathrm{min})\end{array}$ & $\begin{array}{l}\text { Suturing } \\
\text { time } \\
(\mathrm{min})\end{array}$ & $\begin{array}{l}\text { Blood } \\
\text { loss } \\
(\mathrm{mL})\end{array}$ & $\begin{array}{l}\text { Hospital } \\
\text { stay } \\
\text { (days) }\end{array}$ & Complications & Success rate $(\%)$ & $\begin{array}{l}\text { Follow-up } \\
\text { (months) }\end{array}$ \\
\hline Bentas [20] & 11 & 197 & - & 50 & - & Nil & 100 & 12 \\
\hline Gettman [51] & 9 & 138.3 & 62.4 & 50 & 4.7 & Nil & $\begin{array}{l}89 \text {, one patient required open } \\
\text { surgery for repair of pelvic defect }\end{array}$ & 4.1 \\
\hline Patel [56] & 50 & 122 & 20 & 40 & 1.1 & Nil & 96 & 11.7 \\
\hline Palese [55] & 38 & 225.6 & 64.2 & 77.3 & 2.8 & Nil & $\begin{array}{l}\text { 94.7, two patients needed } \\
\text { further therapy }\end{array}$ & 12.2 \\
\hline Siddiq [54] & 26 & 245 & - & 69 & 2 & Fever, urine leak & 95 & 6 \\
\hline
\end{tabular}

tients who underwent robot-assisted pyeloplasty [54]. Of these patients, four had secondary UPJ obstruction. All patients had pre-operative retrograde ureteral stents placed. There were only three minor complications including post-operative fever, a urine leak managed conservatively, and an umbilical hernia. Follow-up with diuretic renal scan was performed 1 month after stent removal and then 6 months later. At 6 months follow-up subjective improvement was $95 \%$ and there was $100 \%$ success with diuretic renal scan.

At the same time, three medical centers in New York City released a collective study of their own robot pyeloplasty experience [55]. The New York collective reported on 35 patients over 3 years, of whom two had a secondary UPJ obstruction. This group did not pre-operatively stent their patients because of their experience with excessive peri-ureteral edema and inflammation in the UPJ. This inflammation may increase the risk of anastomotic leaks and may cause the tissue to be more friable. Mean follow-up was 7.9 months and consisted of a diuretic renal scan at 3 months, then yearly. They reported an overall success rate of $94 \%$.

The largest series of completely robot-assisted laparoscopic pyeloplasties with at least 11 months of follow-up was reported by Patel [56]. Fifty patients all underwent Anderson-Hynes dismembered pyeloplasty (Fig. 5). Most patients were discharged on post-oper- ative day one. Ureteral stents were removed at 3 weeks. Patency of the UPJ was followed by diuretic renal scan at 1 month, then every 3 months in the first year, then every 6 months for the second year, and then yearly. There were no complications, and blood loss was minimal in all cases. Forty-eight of fifty patients $(96 \%)$ had both objective and subjective improvement.

\section{Robotic cystectomy}

In the last two years there has been increasing interest in laparoscopic radical cystectomy and, on the basis of published articles and abstracts, approximately 400 such operations have been performed throughout the world in different centers. These procedures are not free from complications, however-more so if diversion is performed totally intracorporeally $[57,58]$.

Menon et al. [59, 60], after acquiring substantial experience in robotic radical prostatectomy, are credited with expanding the horizon of robotic surgery into the field of bladder cancer.

Robotic radical cystectomy is a procedure which is currently in the developing phase. Most of the series (Table 5) described in the literature use 5-6 ports and a surgical technique developed by Menon et al. [59]. Around the same time, Beecken et al. [61] described the possibility of intracorporeal reconstruction of
Fig. 5 Robotic pyeloplasty patient positioning
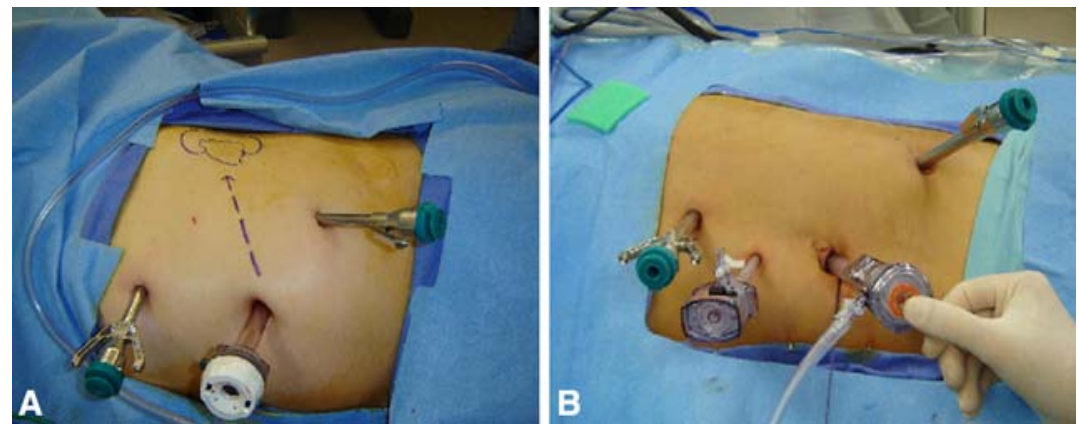
Table 5 Operative characteristics of robotic cystectomy

\begin{tabular}{|c|c|c|c|c|c|}
\hline & $\begin{array}{l}\text { Menon } \\
\text { et al. [59] }\end{array}$ & $\begin{array}{l}\text { Beecken } \\
\text { et al. [61] }\end{array}$ & $\begin{array}{l}\text { Menon } \\
\text { et al. [60] }\end{array}$ & $\begin{array}{l}\text { Hemal } \\
\text { et al. [58] }\end{array}$ & $\begin{array}{l}\text { Balaji } \\
\text { et al. [62] }\end{array}$ \\
\hline Number of cases & 14 men & 1 & 3 & 24 & 1 \\
\hline Number of ports & $5-6$ & Minilaparotomy, 5 & $5-6$ & $5-6$ & 6 \\
\hline Lymphadenectomy & $\begin{array}{l}\text { Bilateral } \\
\text { extended pelvic } \\
\text { lymphadenectomy }\end{array}$ & $\begin{array}{l}\text { Bilateral pelvic } \\
\text { lymphadenectomy }\end{array}$ & $\begin{array}{l}\text { Bilateral } \\
\text { extended pelvic } \\
\text { lymphadenectomy }\end{array}$ & $\begin{array}{l}\text { Bilateral } \\
\text { extended pelvic } \\
\text { lymphadenectomy }\end{array}$ & \\
\hline Operation time (min) & RRC: 140 & RRC + UD: 510 & RRC: $150,160,170$ & RRC: 110 to 170 & 828 \\
\hline & $\begin{array}{l}\mathrm{UD}-120(\mathrm{IC}) \\
168(\mathrm{ONB})\end{array}$ & & UD: $130,190,170$ & UD: 120 to 180 & \\
\hline Blood loss (mL) & $<150$ & 200 & $150,250,100$ & $100-300$ & $\begin{array}{l}500 \text { (decrease } \\
\text { in } \mathrm{Hb} 5.3 \mathrm{~g} \text { ) }\end{array}$ \\
\hline Surgical margins & $\begin{array}{l}\text { Free from tumor } \\
\text { infiltration }\end{array}$ & Negative & Negative & $\begin{array}{l}\text { Free from tumor } \\
\text { infiltration }\end{array}$ & Negative \\
\hline Urinary diversion & $\begin{array}{l}\text { Ileal Coduit: } 2 \\
\text { W-pouch } \\
\text { neobladder: } 9 \\
\text { Double chimney: } 2 \\
\text { T pouch: } 1\end{array}$ & $\begin{array}{l}\text { UD: Hautmann } \\
\text { ileal neobladder } \\
\text { Midline incision } \\
\text { was extended to } \\
\text { exteriorized } \\
\text { ileum for ileo-ileal } \\
\text { anastomosis }\end{array}$ & $\begin{array}{l}\text { Ileal coduit: } 1 \\
\text { W-pouch } \\
\text { neobladder: } 1 \\
\text { T pouch: } 1\end{array}$ & $\begin{array}{l}\text { Ileal coduit: } 4 \\
\text { W-pouch } \\
\text { neobladder: } 16 \\
\text { Double chimney: } 2 \\
\text { T pouch: } 2\end{array}$ & $\begin{array}{r}\text { Intracorporeal } \\
\text { ileal conduit }\end{array}$ \\
\hline $\begin{array}{l}\text { Intraoperative } \\
\text { complications } \\
\text { or conversion }\end{array}$ & None & None & None & None & Ileus \\
\hline
\end{tabular}

orthotopic neobladder in a single case. Later, Balaji et al. [62] described the possibility of intracorporeal reconstruction of the ileal conduit in a patient. Different series of RRC reported in the literature, with intraoperative, perioperative, and post-operative details, are listed in Table 5.

Although robotic radical cystectomy and extracorporeal urinary diversion are difficult procedures to perform, early experiences have shown promise for future innovation. The technique of RRCP has the potential to enable precise and rapid removal of the bladder with minimal blood loss and reduced morbidity. This approach has the advantages of minimally invasive and open surgery. Extracorporeal reconstruction of the urinary diversion requires less operative time at this stage of evolution of laparoscopic and robotic instrumentation.

The development of a technique for performing nerve-sparing robotic radical cystectomy using the da Vinci system is also beneficial for sexually active young patients and is easier to perform in males, because the prostate is benign in these patients. Initial urinary incontinence results show promise, because of excellent apical dissection, preservation of puboprostatic ligaments, sphincter urethrae, and a good urethral stump.

The challenge for the future is to continue to work to distinguish what can be done from what should be done, especially for bladder cancer, where two major components of surgery (extirpative surgery in the form of radical cystectomy and reconstructive surgery for urinary diversion) are mandatory. The long-term follow-up with cancer disease-free and overall survival are currently unknown. It is also important to have randomized series comparing robotic cystectomy with the best open surgery. In the future, with the development of technology, instrumentation, tissue engineering, absorbable endo-GIA bowel stapler, and further refinement of technique, it may be possible to perform the entire procedure completely intracorporeally with equal efficiency. The initial results look promising although the final determining factor will ultimately depend on long-term oncologic results.

\section{Robotic adrenalectomy}

Laparoscopic adrenalectomy is now regarded as the preferred surgical approach for the management of benign adrenal disease. Despite the benefits of laparoscopic adrenalectomy, the procedure has shortcomings that are shared by other laparoscopic techniques. Commonly noted problems include the absence of 3D perception, minimal tactile feedback, reduced dexterity compared with open surgery and poor ergonomics for the surgeon (Table 6).

The da Vinci-assisted adrenalectomy was first reported in 2001 by Horgan et al. [63] who described a 
Table 6 Operative characteristics and outcomes of robot-assisted laparoscopic adrenalectomy

\begin{tabular}{llllll}
\hline Investigators & $\begin{array}{l}\text { Patients } \\
(N)\end{array}$ & $\begin{array}{l}\text { OR time } \\
(\mathrm{min})\end{array}$ & $\begin{array}{l}\text { Conversion } \\
\text { rate }(\%)\end{array}$ & Complications & Remark \\
\hline Bentas [78] & 4 & & 0 & Nil & Technically feasible \\
Desai [79] & 2 & $110-165$ & 0 & Nil & Hospital stay was 2 and 3 days \\
Brunaud [80] & 14 & 111 & 7 & To continue further evaluation of robotic system \\
Beninca [81] & 9 & 82.1 & 44.4 & Nil & High operative time and cost of the procedure \\
Morino [65] & 10 & 169.2 & 40 & $20 \%$ morbidity & - \\
\hline
\end{tabular}

total of 34 da Vinci-assisted laparoscopic cases. More recently Winter et al. [64] described their experience of 30 robotic adrenalectomies. This is currently the largest series. Median operative time was $185 \mathrm{~min}$ and median hospital stay was 2 days. Surprisingly, hospital charges for robotic adrenalectomy $(\$ 12,977)$ were not significantly different from charges for traditional laparoscopic $(\$ 11,599)$ or open adrenalectomy $(\$ 14,600)$. In contrast Morino et al. [65] randomized patients to a laparoscopic arm and a robotic arm when performing adrenalectomy. Operative times were significantly longer for the robot group; conversion to standard laparoscopy was necessary for four of ten robot patients. Finally, the total cost of the procedure was significantly higher than that for the laparoscopic group.

Agreement on the advantages of robotic adrenalectomy over laparoscopic adrenalectomy has yet to be reached.

\section{Urogynecology}

There are few reports in the urogynecology and gynecology literature of results from the use of robotics. Robotics have been used to perform hysterectomies, for repair of vesicovaginal fistula, and for sacrocolpopexy. Transabdominal robotic sacrocolpexy has recently emerged as a new minimally invasive approach to the treatment of vaginal vault prolapse. Elliott et al. [66] recently described their experience with 30 patients. Mean follow-up was 24 months, mean operative time was $3.1 \mathrm{~h}$, and all but one patient went home on post-operative day one. One patient developed a grade 3 rectocele, one had a recurrent vault prolapse, and two had vaginal extrusion of mesh.

Vesicovaginal fistula (VVF) repair has also recently been completed with use of robotics. The first case of VVF repair using a laparoscopic approach with da Vinci robotic assistance was reported by the University of California, Irvine [67]. In 2006, Sundaram et al. [68] published data on VVF repair using robotics only. Fistula repair was successful in all cases, with a mean operative time of $233 \mathrm{~min}$ and estimated blood loss of less than $70 \mathrm{~mL}$. The foley catheter was removed on the 10th post-operative day after voiding cystourethrography. At 6 months follow-up these patients continued to void normally without any recurrence of VVF.

Further long-term follow-up will be necessary to see if robotic assistance has technical advantages during complex laparoscopic female urologic procedures.

\section{Pediatric urology}

Current procedures performed using robotics includes pyeloplasty, ureteral reimplantation, continent urinary diversions, and bladder augmentation. The $7-\mathrm{cm}$ distance between the robotic ports may be difficult to achieve with children and infants. The recent introduction of $5 \mathrm{~mm}$ instruments has spurred significant interest in the development of robotic pediatric urology applications.

Yee et al. [69] compared eight pediatric patients who underwent robot-assisted laparoscopic pyeloplasty with eight patients who underwent conventional open pyloplasty. A four-port transperitoneal technique was used to perform Anderson-Hynes pyeloplasty. The mean operative time and estimated blood loss was $363 \mathrm{~min}$ and $13.1 \mathrm{~mL}$, respectively, in the robot-assisted group compared with $248 \mathrm{~min}$ and $53.8 \mathrm{~mL}$ in the open group. At a mean follow-up of 14.7 months, all robotic procedures were successful as determined by subjective data using pain scales and radiological data.

Peters et al. [70] have also described extra-vesical Lich Gregoir and transvesical Cohens reimplantation. Twenty-one children underwent an unilateral ureteral reimplantation and three children underwent a bilateral ureteral reimplantation. Operative times ranged from $2 \mathrm{~h}$ for unilateral to $3 \mathrm{~h}$ for the bilateral procedure. At follow-up of just under 9 months 21 of the 27 patients had a satisfactory outcome [70].

Pedraza et al. [71] reported their case report with laparoscopic appendicovesicostomy using the da Vinci 
robotic system. The patient was a 7-year-old boy with a history of posterior urethral valves. A four port transperitoneal approach was used. Overall operative time was $6 \mathrm{~h}$. Estimated blood loss was $10 \mathrm{~mL}$. There were no intraoperative or post-operative complications. The patient was discharged home on post-operative day 4 . During the procedure the utility of the robot was most helpful with the appendicovesical anastomosis. Use of the robot helped create a water-tight anastomosis and reduced the overall operative time of the procedure.

Miniaturization of robotic systems and instruments is expected to further encourage expansion of pediatric urologic applications.

\section{Other procedures}

Robotic surgery has even entered the realm of microsurgery [46]. Robot-assisted vasovasostomies have been performed in the rat model with 10-0 suture using a two layered technique. All anastomosis were patent, and all rabbits were free from crush injury [72]. Similar to other studies, tremor is eliminated; clear visualization of microscopic details is available; and knot tying and suture placement is facilitated with the six degrees of freedom in movement and motion downscaling software. The mean operative time was longer for the robot-assisted vasovasostomy than for traditional microscopic vasovasostomy (75 and $42 \mathrm{~min}$, respectively).

Schoor et al. [73] devised a model vas deferens system using rat vasa deferentia and completed vasal anastomosis with full-thickness and mucosal robotically placed, Sharpoint 10-0 bicurve nylon sutures. Experienced and inexperienced microsurgeons performed separate anastomoses. Both groups of microsurgeons completed anastomoses with "accuracy and enhanced comfort".

Although robot-assisted vasovasostomy is associated with increased operative times, the absence of adverse haptic events and comparable patency continue to suggest a possible role for robotics in microsurgery.

\section{Telepresence surgery}

Telepresence surgery is defined as the ability to perform surgery remote from the patient's bedside by application of robotic technology. Telepresence surgery and robotic telementoring are two revolutionary applications achieved by linking a robot to a telecommunication system. In telerobotic procedures, the surgeon operates from the surgeon's console, which is a few feet or thousands of miles away from the slave robotic system. The introduction of robotics into the realm of laparoscopic surgery has given rise to significant interest in telepresence surgery. Electronic links using existing communication lines connect the remote surgeon to the robot and enable the surgeon to operate. The adoption of telepresence surgical capability has many potential implications. It would enable staff at centers of excellence to perform surgery at other institutions across the country and the world without leaving their centers. Telepresence surgical devices enable surgeons from remote sites to telementor surgeons still developing skills. The first major transatlantic surgery was a telerobotic cholecystectomy performed by surgeons in New York, NY, USA, on a patient in Strasbourg, France in 2001 [32, 74].

Telepresence surgery raises a host of ethical dilemmas. Patient privacy, speed of transmission, and responsibility for the care of the patient are critical issues when dealing with a surgeon at the bedside and a surgeon operating from a remote location and will need to be addressed before incorporation of this technology [63].

\section{The future}

Robotic technology has undoubtedly revolutionized the way many surgical procedures are performed today and will be performed in the future. Over the last five years we have taken the unique advantages of the da Vinci system and used them to make urologic surgery more refined.

Additional technical modifications of robotic systems may increase the effectiveness of robotic surgery. One important issue is the use of smaller instruments. In the latest version of the da Vinci system there is the addition of 5-mm instruments, use of the fourth arm and a new vision system, which enables switching between the three-dimensional close-up view to a more wide-angle view [63].

Other potential topics of research include use of miniaturized motors to reduce the size of the robotic tower, evaluating the potential for mounting the robotic tower on the ceiling or wall to increase access points to the patient, and real-time or non-real time image integration into the endoscopic view on the console. Image integration would enable the surgeon to operate on the target organ and evaluate blood supply by use of real-time ultrasound, or identify a lesion by integrating magnetic resonance imaging (MRI)/CT images into the operative image (personal communication with Intuitive Surgical). 
From an educational perspective, significant research is currently in progress to produce a mentoring system. This system would enable an attending surgeon to have control over the "masters" if problems should arise during a case performed by a resident/fellow. Research on robotic simulators is also being conducted. Robotic simulators are, potentially, a safe learning environment enabling objective and reliable quantification of skill levels by trainers [63].

\section{Conclusion}

There has been exponential growth in the use of robotic technology in urology during the last decade. Because prostate cancer is the most prevalent male cancer in the United States, robotic prostatectomy has grown as a minimally invasive alternative to open prostatectomy. The technology has been especially useful for procedures requiring intricate suturing or maneuverability in small spaces, for example pyeloplasty and prostatectomy. As the number of robotic systems and surgeon experience increase, adaptation of robotic procedures will undoubtedly increase in number with decreasing operative times. With continual modification of robotic technology, for example miniaturization of instruments and image integration, robotic applications in urology will continue to advance in the future.

\section{References}

1. Schuessler WW, Schulam PG, Clayman RV, Kavoussi LR (1997) Laparoscopic radical prostatectomy: initial short-term experiences. Urology 50:854-857

2. Wieder JA, Soloway MS (1998) Incidence, etiology, location, prevention and treatment of positive surgical margins after radical prostatectomy for prostate cancer. J Urol 160:299-315

3. Han M, Partin AW, Chan DY, Walsh PC (2004) An evaluation of the decreasing incidence of positive surgical margins in a large retropubic prostatectomy series. J Urol 171(1):23-26

4. Guillonneau B, Jayet C, Tewari A, Vallancien G (2001) Robot-assisted laparoscopic nephrectomy. J Urol 166:200-201

5. Horgan S, Vanuno D, Sileri P, Cicalese L, Benedetti E (2002) Robot-assisted laparoscopic donor nephrectomy for kidney transplantation. Transplantation 73:1474-1479

6. Phillips CK, Taneja SS, Stifelman MD (2005) Robot-assisted laparoscopic partial nephrectomy: NYU technique. J Endourol 19(4):441-445

7. Pechel R, Gettman M, Bartsch G (2003) Robot-assisted laparoscopic pyeloplasty: initial clinical results. Eur Urol 2(1) (Suppl 2):46

8. Caruso RP, Phillips CK, Kau E, Taneja SS, Stifelman MD (2006) Robot-assisted laparoscopic partial nephrectomy: initial experience. J Urol 176(1):36-33

9. Sung G, Gill I, Hsu T (1999) Robot-assisted laparoscopic pyeloplasty: a pilot study. Urology 53:1099-1103
10. Walsh PA, Marschke P, Ricker D, Burnett AI (2000) Patient reported urinary continence and sexual function after anatomic radical prostatectomy. Urology 55(1):58-61

11. Pasticier G, Rietbergen JB, Guillonneau B, Fromont G, Menon M, Vallancien G (2001) Robotically assisted laparoscopic radical prostatectomy: feasibility study in men. Eur Urol 40(1):70-74

12. Abbou CC, Hoznek A, Salomon L, Olsson LE, Lobontiu A, Saint F et al (2001) Laparoscopic radical prostatectomy with a remote controlled robot. J Urol 165(6 Pt 1):1964-1966

13. Binder J, Kramer W (2001) Robotically assisted laparoscopic radical prostatectomy. BJU Int 87(4):408-410

14. Rassweiler J, Frede T, Seemann O, Stock C, Sentker L (2001) Telesurgical laparoscopic radical prostatectomy. Initial experience. Eur Urol 40(1):75-83

15. Menon M, Tewari A (2003) Robotic radical prostatectomy and the Vattikuti Urology Institute technique: an interim analysis of results and technical points. Urology 61(4 Suppl 1):15-20

16. Menon M, Tewari A, Peabody J (2003) Vattikuti Institute prostatectomy: technique. J Urol 169(6):2289-2292

17. Menon M, Tewari A, Baize B, Guillonneau B, Vallancien G (2002) Prospective comparison of radical retropubic prostatectomy and robot-assisted anatomic prostatectomy: the Vattikuti Urology Institute experience. Urology 60(5):864-868

18. Ahlering TE, Skarecky D, Lee D, Clayman RV (2003) Successful transfer of open surgical skills to a laparoscopic environment using a robotic interface: initial experience with laparoscopic radical prostatectomy. J Urol 170(5):1738

19. Menon M, Shrivastava A, Tewari A, Sarle R, Hemal A, Peabody JO et al (2002) Laparoscopic and robot-assisted radical prostatectomy: establishment of a structured program and preliminary analysis of outcomes. J Urol 168(3):945-949

20. Wolfram M, Brautigam R, Engl T, Bentas W, Heitkamp S, Ostwald $M$ et al (2003) Robot-assisted laparoscopic radical prostatectomy: the Frankfurt technique. World J Urol 21(3):128-132

21. Bentas W, Wolfram M, Jones J, Brautigam R, Kramer W, Binder J (2003) Robotic technology and the translation of open radical prostatectomy to laparoscopy: the early Frankfurt experience with robotic radical prostatectomy and one year follow-up. Eur Urol 44(2):175-181

22. Ahlering TE, Woo D, Eichel L, Lee DI, Edwards R, Skarecky DW (2004) Robot-assisted versus open radical prostatectomy: a comparison of one surgeon's outcomes. Urology 63(5):819-822

23. Patel VR, Tully AS, Holmes R, Lindsay J (2005) Robotic radical prostatectomy in the community setting-the learning curve and beyond: initial 200 cases. J Urol 174(1):269-272

24. Tewari A, Srivasatava A, Menon M (2003) A prospective comparison of radical retropubic and robot-assisted prostatectomy: experience in one institution. BJU Int 92(3):205210

25. Cathelineau X, Rozet F, Vallancien G (2004) Robotic radical prostatectomy: the European experience. Urol Clin North Am 31(4):693-699, viii

26. Ahlering TE, Eichel L, Edwards RA, Lee DI, Skarecky DW (2004) Robotic radical prostatectomy: a technique to reduce pT2 positive margins. Urology 64(6):1224-1228

27. Kwoh YS, Hou J, Jonckheere EA, Hayati S (1988) A robot with improved absolute positioning accuracy for CT guided stereotactic brain surgery. IEEE Trans Biomed Eng 35:153160

28. Davies BL, Hibberd RD, Coptcoat MJ et al (1989) A surgeon robot prostatectomy-a laboratory evaluation. J Med Eng Technol 13:273-277 
29. Bann S, Khan M, Hernandez J, Munz Y, Moorthy K Datta V et al (2003) Robotics in surgery. J Am Coll Surg 196:784-795

30. Bauer A, Borner M, Lahmer A (1999) Clinical experience with a medical robotic system for total hip replacement. In: Nolte LP, Ganz R (eds) Computer assisted orthopedic surgery. Hogrefe and Huber, Bern, pp 128-133

31. Satava RM (2003) Robotic surgery: from past to future-a personal journey. Surg Clin N Am 83:1-6

32. Marescaux J, Rubino F (2003) The Zeus robotic system: experimental and clinical applications. Surg Clin N Am 83:19

33. Webster TM, Herrell SD, Chang SS, Cookson MS, Baumgartner RG, Anderson LW, Smith Ja Jr (2005) Robot-assisted laparoscopic radical prostatectomy versus retropubic radical prostatectomy: a prospective assessment of postoperative pain. J Urol 174(3):912-914

34. Menon M, Hemal AK, Tewari A, Shrivastava A, Bhandari A (2004) The technique of apical dissection of the prostate and urethrovesical anastomosis in robotic radical prostatectomy. BJU Int 93:715-719

35. Eastam J, Scardino P (2002) Radical Prostatectomy. Campbell's Urology, 4th edn, Ch 89:3080-3106, Saunders Publishing, Philadelphia

36. Fowler FJ Jr, Barry MJ, Lu-Yau G et al (1993) Patient-reported complications and follow-up treatment after radical prostatectomy. Urology 42:622-629

37. Geary Es, Dendinger TE, Frieha FS et al (1995) Nerve sparing radical prostatectomy: a different view. J Urol 154:145-149

38. Geary ES, Dedinger TE, Frieha FS et al (1995) Incontinence and vesical neck strictures following radical retropubic prostatectomy. Urology 45:1000-1006

39. Talcott JA, Ricker P, Propert KJ et al (1997) Patient reported impotence and incontinence after nerve sparing radical prostatectomy. J NCI 89:1117-1123

40. Walsh PC (2000) Patient-reported urinary continence and sexual function after anatomic radical prostatectomy. J Urol 164:242

41. Lepor H, Nieder AM, Fraiman MC (2001) Early removal of urinary catheter after radical retropubic prostatectomy is both feasible and desirable. Urology 58:425

42. Walsh PC, Partin AW, Epstein JI (1994) Cancer control and quality of life following anatomical radical retropubic prostatectomy: results at 10 years. J Urol 152:1831-1836

43. Catalona WJ, Basler JW (1993) Return of erections and urinary continence following nerve sparing radical retropubic prostatectomy. J Urol 150:905-907

44. Eastham JA, Kattan MW, Roger SE et al (1996) Risk factors for urinary incontinence after radical prostatectomy. J Urol 156:1707-1713

45. Palapattu JS, Stapelton AM, Seale-Hawkins Ck et al (1996) A change in technique in radical retropubic prostatectomy markedly improves post operative potency. J Urol 155:647a

46. Lepor H, Nieder AM, Ferrandino MN (2001) Intraoperative and post-operative complications of radical retropubic prostatectomies in a consecutive series of 1000 cases. J Urol 166:1729

47. Catalona WJ, Carvalhal GF, Mager DE, Smith DS (1999) Potency, continence, and complication rates in 1870 consecutive radical retropubic prostatectomies. J Urol 162:433438

48. Quinlan DM, Epstein GI, Carter BS, Walsh PC (1991) Sexual function following radical prostatectomy: influence of preservation of neurovascular bundles. J Urol 145:998-1002

49. Menon M, Kaul S, Bhandari A, Shrivastava A, Tewari A, Hemal A (2005) Potency following robotic radical prosta- tectomy: a questionnaire based analysis of outcomes after conventional nerve sparing and prostatic fascia sparing techniques. J Urol 174:2291-2296

50. Sung G, Gill I (2001) Robotic laparoscopic surgery: a comparison of the da Vinci and Zeus systems. Urology 58:893898

51. Gettman M, Neururer R, Bartsch G (2002) Anderson-Hynes dismembered pyeloplasty performed using the da Vinci robotic system. Urology 60:509-513

52. Gettman M, Peschel R, Neururer R (2002) A comparison of laparoscopic pyeloplasty performed with the da Vinci robotic system versus standard laparoscopic techniques: initial clinical results. Eur Urol 42:453-458

53. Peschel R, Neururer R, Bartsch G (2004) Robotic pyeloplasty: technique and results. Urol Clin North Am 31:737-741

54. Siddiq F, Leveillee R, Villicana R (2005) Computer-assisted laparoscopic pyeloplasty: University of Miami experience with da Vinci surgical system. J Endourol 19:387-392

55. Palese MA, Stifelman MD, Munver Rl (2005) Robot-assisted laparoscopic dismembered pyeloplasty: a combined experience. J Endourol 19:382-386

56. Patel V (2005) Robot-assisted laparoscopic dismembered pyeloplasty. Urology 66:45-49

57. Goel A (2004) External iliac vein injury and its repair during laparoscopic radical cystectomy. JSLS 8(1):81-83

58. Hemal AK, Kumar R, Seth A, Gupta NP (2004) Complications of laparoscopic radical cystectomy during the initial experience. Int Urol 11(7):483-488

59. Menon M, Hemal AK, Tewari A, Shrivastava A, Shoma AM, El-Tabey NA, Shaaban A, Abol-Enein H, Ghoneim MA (2003) Nerve-sparing robot-assisted radical cystoprostatectomy and urinary diversion. BJU Int 92(3):232-236

60. Menon M, Hemal AK, Tewari A, Shrivastava A, Shoma AM, Abol-Ein H, Ghoneim MA (2004) Robot-assisted radical cystectomy and urinary diversion in female patients: technique with preservation of the uterus and vagina. J Am Coll Surg 198(3):386-393

61. Beecken WD, Wolfram M, Engl T et al (2003) Robot-assisted laparoscopic radical cystectomy and intra-abdominal formation of an orthotopic ileal neobladder. Eur Urol 44(3):337-339

62. Balaji KC, Yohannes P, McBride CL, Oleynikov D, Hemstreet GP 3rd (2004) Feasibility of robot-assisted totally intracorporeal laparoscopic ileal conduit urinary diversion: initial results of a single institutional pilot study. Urology 63:51-55

63. Horgan S, Vanuno D (2001) Robots in laparoscopic surgery. J Laparoendosc Adv Surg Tech A 11(6):415-419

64. Winter JM, Talamini MA, Stanfield CL, Chang DC, Hundt JD, Duckiw AP, Campbell KA, Schulick RD (2006) Thirty robotic adrenalectomies: a single institution's experience. Surg Endosc 20(1):119-124

65. Morino M, Beninca G, Giraudo G, Del Genico GM, Rebecchi F, Garrone C (2004) Robot-assisted vs laparoscopic adrenalectomy: a prospective randomized controlled trial. Surg Endosc 18(12):1742-1746

66. Elliott D, Krambeck A, Chow G (2006) Long-term results of robot-assisted laparoscopic sacrocolpopexy for the treatment of high grade vaginal vault prolapse. J Urol 176:655-659

67. Eichel L, Ahlering T, Clayman R (2004) Role of robotics in laparoscopic urologic surgery. Urol Clin North Am 31:781792

68. Sundaram BM, Kalidasan G. Hemal K (2006) Robotic repair of vesicovaginal fistula: case series of five patients. Urology 67(5):970-973 
69. Yee DS, Shanberg AM, Duel BP, Rodriguez E, Eichel L, Rajpoot D (2006) Initial comparison of robot-assisted laparoscopic versus open pyeloplasty in children. Urology 67(3):599-602

70. Peters CA (2004) Laparoscopic and robotic approach to genitourinary anomalies in children. Urol Clin North Am 31:595-605

71. Pedraza R, Weiser A, Franco I (2004) Laparoscopic appendicovesicostomy using the da Vinci robotic system. J Urol 171:1652-1653

72. Kuang W, Shin PR, Oder M, Thomas AJ Jr (2005) Robotassisted vasovasostomy: a two-layer technique in an animal model. Urology 65(4):811-814

73. Schoor RA, Ross L, Niederberger C (2003) Robot-assisted microsurgical vasal reconstruction in a model system. World J Urol 21(1):48-49

74. Dharia SP, Falcone T (2005) Robotic in reproductive medicine. Fertil Steril 84:1-11

75. Renoult E, Hubert J, Ladriere M, Billaut N, Feuillu B, Kessler M (2006) Robot-assisted laparoscopic and open live-donor nephrectomy: a comparison of donor morbidity and early renal allograft outcomes. Nephrol Dial Transplant 21:472-477
76. Gettman MT, Blute ML, Chow GK, Neururer R, Bartsch G, Peschel R (2004) Robotic-assisted laparoscopic partial nephrectomy: technique and initial clinical experience with da Vinci robotic system. Urology 64:914-918

77. Pedraza R, Palmer L, Moss V, Franco I (2004) Bilateral robotic assisted laparoscopic heminephoureterectomy. J Urol 171:2394-2395

78. Bentas W, Wolfram M, Brautigam R, Binder J (2002) Laparoscopic transperitoneal adrenalectomy using a remotecontrolled robotic surgical system. J Endourol 16:373-376

79. Desai MM, Gill IS, Kaouk JH, Matin SF, Sung GT, Bravo EL (2002) Robotic-assisted laparoscopic adrenalectomy. Urology 60:1104-1107

80. Brunaud L, Bresler L, Ayav A, Tretou S, Cormier L, Klein M, Boissel P (2003) Advantages of using robotic Da Vinci system for unilateral adrenalectomy: early results. Ann Chir 128:530-535

81. Beninca G, Garrone C, Rebecchi F, Giaccone C, Morino M (2003) Robot-assisted laparoscopic surgery. Preliminary results at our center. Chir Ital 55:321-331 